\title{
Factores de unidad compositiva en el Protréptico de Clemente Alejandrino: movimiento, polaridad y simetría
}

\author{
Miguel HERRERo DE JÁUREGUI \\ Universidad Complutense de Madrid \\ miguelherrero@filol.ucm.es
}

\section{EL BÁLSAMO DE PERSUASIÓN Y SU MISTERIOSA RECETA}

El Protréptico, la exhortación a la conversión escrita a finales del siglo II por Clemente de Alejandría, ha gozado de singular fortuna entre los estudiosos modernos de la literatura cristiana antigua. Por un lado, su abundante y precisa información sobre la religión, mitología y filosofía griegas han hecho de la obra una preciosa fuente de datos desconocidos por otras vías, y por otro, la altura de su estilo la hace el mejor exponente del cristianismo helenizado, que compite en calidad literaria con otras obras cumbre de la época antonina. Finalmente, su carácter introductorio al resto de la obra clementina ha servido a los estudiosos tradicionalmente para buscar en ella apuntes que iluminen el sentido de pasajes del Pedagogo y los Stromata. Sin embargo, quizá por esta multiplicidad de intereses, son pocos los estudios que atiendan al conjunto de la obra más allá de la explicación de determinados pasajes ${ }^{1}$. El propósito de las páginas que siguen es aportar cierta luz sobre la composición y sentido del Protréptico, cuyo mayor valor y razón última de su éxito entre antiguos y modernos estriba, a mi entender, en la combinación exitosa y original de diferentes modelos literarios y fuentes muy distintas en un texto permeado de notable unidad. En buena medida, la fuerza retórica de la obra proviene de la integración de componentes de muy diversa procedencia en un producto novedoso.

El propio Clemente es consciente de esta novedad y la proclama orgulloso al principio del Protréptico, que define como un nuevo canto, contrapuesto a los antiguos mitos y los ritmos musicales de los griegos:

Mi Éunomo canta no la canción de Terpandro, ni de Cepión, ni la frigia, lidia o doria, sino la melodía eterna de la nueva armonía, que lleva el nombre de Dios, la nueva canción, la de los levitas, que «disipa el dolor y la cólera, la que se olvida

\footnotetext{
${ }^{1}$ El estudio literario más completo del Protréptico es H. Steneker, Peithous demiourgia: observations sur la fonction du style dans le Protréptique de Clément d'Alexandrie, Nijmegen, 1967.
} 
de todos los males» (Od. 4. 221). En su canción mezcla un cierto dulce y verdadero bálsamo de persuasión ${ }^{2}$.

La nueva canción queda definida, con buscada paradoja, por una doble referencia a la tradición antigua, la hebrea y la griega: la bíblica con el adjetivo levítico, y otra a la homérica con un famoso verso referido al vino que se recitaba con fines terapéuticos ${ }^{3}$. Como por asociación con este uso médico del verso homérico, la frase siguiente define su canto como un $\varphi \alpha ́ \rho \mu \alpha \kappa o v ~ \pi \varepsilon \imath \theta$ ov $\varsigma$, un remedio de persuasión ${ }^{4}$. Y a su vez define la

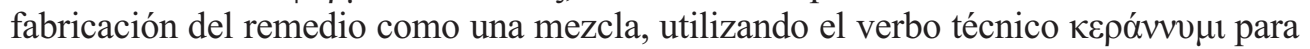
mezclar el vino con agua para el banquete. En esta frase late sin duda la concurrencia con la embriaguez dionisiaca, condenada en el párrafo anterior frente a la sensatez cristiana $^{5}$. Pero además queda claro que Clemente concibe su obra como una mezcla de elementos varios que, para lograr inculcar la verdad ( $\alpha \lambda \eta \theta$ เvóv), debe ser dulce ( $\gamma \lambda v \kappa v ́)$ y persuasiva $(\pi \varepsilon \imath \theta$ oṽ $\varsigma$ ) como el vino. Por ello la traducción castellana más atinada de este pharmakon clementino parece el bálsamo, que tiene iguales resonancias con nuestro Quijote que el verso homérico para el lector griego de la época.

Más allá de la traducción de pharmakon, el interés de la propia definición de Clemente de su empresa literaria está en la conciencia de que es necesaria una mezcla hábil y proporcionada de diversos ingredientes. Contrariamente al Pedagogo y los Stromata, en el Protréptico la complejidad de esta combinación no está en el plano teológico y filosófico, pues los contenidos ideológicos son relativamente simples, sino en el literario y retórico: las fuentes, los estilos, las alusiones y las imágenes. No han faltado estudios minuciosos de la obra a la búsqueda de sus fuentes y modelos literarios, y han logrado notable éxito en diseccionar prácticamente todos los elementos que componen el Protréptico. Vale la pena un breve repaso a los resultados de esta labor de análisis.

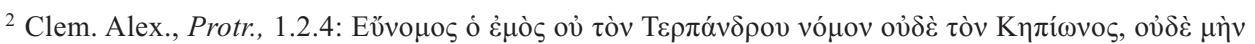

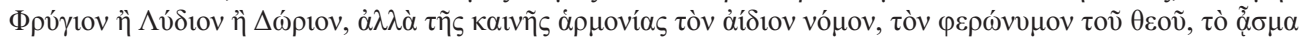

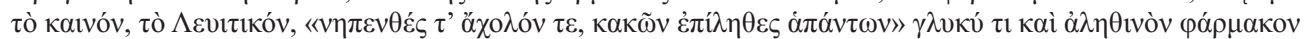

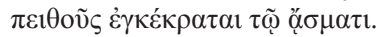

${ }^{3}$ El verso de $O d .4 .221$, referido a la mezcla preparada por Helena en Egipto (una referencia quizá popular en contexto alejandrino), se recitaba en curaciones milagrosas, como hizo Empédocles según Jámblico ( $V P$ 113); Luciano (Salt. 79) y Dión Crisóstomo (Or. 12.52) lo interpretan como símbolo de la catarsis psíquica que cura el alma. A este uso de tono pitagórico del verso homérico hay que sumar la tradición apologética, que lo utilizaba para demostrar la dependencia griega de Egipto, y por ende de la revelación bíblica (cfr. Ps.-Iust. Cohort. 28.2, con el comentario ad loc. de C.. Riedweg, Ps.-Justin (Markellos von Ancyra?) Ad Graecos de vera religione (bisher Cohortatio ad Graecos): Einleitung und Kommentar, Basel 1994.). Es posible que la yuxtaposición del verso con el canto levítico aluda a esta interpretación del verso, pues Clemente conocía la teoría de la dependencia (cf. Protr. 6.70.1).

${ }^{4}$ Es la lección del manuscrito, defendible (con M. Marcovich, Clementis Alexandrini Protrepticus, Leiden $1995)$ frente a la conjetura $\pi \varepsilon ́ v \theta o v \varsigma$ aceptada por O. Stählin, Clemens Alexandrinus I: Protrepticus und Paedagogus, Leipzig $1905\left(1972^{3}\right.$ ) por el paralelo no sólo con Longino (Art. Rhet. 190.12) sino con el Fedro platónico (274e, 275a): en Protr. 10.103.1 y 10.106.2 retoma el motivo del pharmakon.

${ }^{5}$ Protr. 1.2.1-2, y en el cierre anular de la obra en 12.119.1-3. Sobre la oposición a Dioniso en la obra, $c f r$. F. Jourdan, «Dionysos dans le Protréptique de Clément d'Alexandrie», Revue d'Histoire des Religions 223.3 (2006), pp. 265-282.
} 
Respecto a las fuentes directas, por un lado, las referencias y citas bíblicas del Antiguo y Nuevo Testamento son constantes a lo largo del texto y lo enraízan sólidamente en la Escritura ${ }^{6}$. Por otro, la abundancia de citas de poetas y filósofos griegos, así como las alusiones, críticas en su mayoría, a mitos, santuarios y rituales paganos entroncan a Clemente con la literatura apologética cristiana previa ${ }^{7}$. A su vez, su conocimiento de los autores del judaísmo helenístico es superior al de sus contemporáneos y precedentes cristianos, pues no se limita a utilizar los materiales tradicionales de las antologías apologéticas, sino que se sirve directamente y con profusión de sus obras doctrinales, especialmente de Filón ${ }^{8}$. A ello hay que añadir que la amplia cultura del alejandrino, que iba mucho más allá de la familiaridad directa con Homero, Eurípides, Heráclito y Platón, y su fácil acceso a literatura pagana en la capital cultural del Mediterráneo oriental, amplió el bagaje de la apologética cristiana de modo notable con la transmisión de datos literarios y religiosos que son resultado de su conocimiento directo de tratadistas griegos ${ }^{9}$.

Los modelos literarios ejercen un influjo más sutil que el mero préstamo de citas y materiales. La Biblia ofrece también a Clemente rasgos estilísticos que imitar en determinadas ocasiones, en contraste con su registro habitual, próximo a la prosa de las escuelas retóricas ${ }^{10}$. A su vez, la apologética cristiana ofrece argumentaciones tópicas sobre los mitos, poetas y estatuas griegas a las que el alejandrino consigue dar nuevo brillo retórico ${ }^{11}$. Entre las fuentes paganas, el Fedro de Platón ha sido considerado un modelo semiconsciente del Protréptico cuyo influjo permea toda la obra, debido a la coincidencia de locuciones e imágenes. El eco e incluso imitación del Fedro, por otro lado, era muy común en la literatura del siglo II d. C. ${ }^{12}$. Ello nos

\footnotetext{
${ }^{6}$ Sobre el fundamento escriturístico del pensamiento clementino, $c f r$. C. Mondésert, Clément d'Alexandrie: Introduction à l'étude de sa pensée religieuse à partir de l'Écriture, Paris, 1944.

${ }^{7}$ N. Zeegers-Van der Vorst, Les citations paiennes dans les apologistes grecs du II siècle, Louvain 1972.

8 J. C. M. van Winden, «Quotations from Philo in Clement of Alexandria's Protrepticus», Vig Christ 32 (1978), pp. 208-213; A. Van der Hoek, «The Catechetical School of Early Christian Alexandria and its Philonic Heritage», HThR 90.1 (1997), pp. 59-87; más en general, D. T. Runia, Philo in Early Christian Literature, Minneapolis, 1993.

${ }^{9}$ Sobre fuentes específicas, $c f r$. p. ej. P. Valentin, «Héraclite et Clément d'Alexandrie», Rech Sc Rel 46 (1958), pp. 27-59; H. Wiese, Heraklit bei Klemens von Alexandrien, Kiel 1963; M. Herrero de Jáuregui, «Las fuentes de Clem. Alex. Protr. 2.12-22: un tratado sobre los misterios y una teogonía órfica», Emerita (2007), pp. 1-32. Sobre las fuentes paganas de Clemente en general, aunque las conclusiones específicas sean muchas veces indemostrables, es útil la Quellensforschung de W. Bousset, Jüdisch-Christlicher Schulbetrieb in Alexandria und Rom: Literarische Untersuchungen zu Philo und Clemens von Alexandria, Justin und Irenäus, Göttingen, 1915; las especulaciones de J. Gabrielsson, Über die Quellen des Clemens Alexandrinus, Uppsala, 1906-09, con el fantasmal Favorino como fuente ubicua, nunca han gozado de aceptación.

${ }^{10}$ Frente a las posiciones extremas de Mondésert, op. cit., p. 71 (Clément a un style tout scripturaire), y E. Norden, Die Antike Kunstprosa, Stuttgart, 1958 II, 520, que sostiene que Clemente se avergonzaba del estilo de los LXX y lo trataba de esconder al máximo, da con la clave intermedia H. Steneker, op. cit., pp. 110-114. Como ejemplos, Protr. 27.2, 94.2, 99.3, 103.3, 106.4-5, 114.2, 120.2-5.

${ }^{11}$ Cfr. H. Chadwick, Early Christian Thought and the Classical Tradition: Studies in Justin, Clement and Origen, Oxford, 1966.

${ }_{12}$ G. W. Butterworth, «Clement of Alexandria's Protrepticus and the Phaedrus of Plato», CQ 10 (1916), pp. 198-205. Cfr. M. B. Trapp, «Plato’s Phaedrus in Second Century Greek Literature», D. A. Russell (ed.), Antonine Literature, Oxford 1990, pp. 141-174, esp. p. 154.
} 
lleva al más evidente foco de comparación con la obra más claramente retórica de Clemente, la oratoria impregnada de las ideas estéticas de la Segunda Sofística: si bien la diatriba popular de las escuelas filosóficas influye en toda la apologética a la hora de atacar la religión rival, en el nivel elevado un rétor como Dión de Prusa utiliza imágenes y locuciones muy similares a las que encontramos en el Protréptico ${ }^{13}$. La propia estructura de la obra, dividida claramente en exordio (capítulo I), refutatio (II-VI), argumentatio (VII-XI) y peroratio (XII), y con una composición en anillo perceptible en las correspondencias entre los capítulos de la primera mitad y los de la segunda, la sitúa en la órbita de la tratadística retórica contemporánea, y los preceptos estilísticos y de organización del discurso de Menandro se cumplen con rigor ${ }^{14}$. Finalmente, el propio título de la obra remite expresamente a la tradición del género protréptico: la obra homónima de Aristóteles es el modelo, directo o indirecto, del texto de Clemente, como lo será después de Jámblico ${ }^{15}$.

Ahora bien, Clemente sigue todos estos modelos, pero su obra no encaja plenamente en ninguno de ellos, precisamente por la mezcla de géneros y contenidos que alberga. A la exhortación a la filosofía del modelo aristotélico se añade la especulación imaginativa propia del Fedro, y los brillantes pasajes retóricos comparables a los discursos de Dión alternan con listas de citas y acusaciones propias de la apologética cristiana. Sin embargo, es claro que la obra clementina, si bien no logra siempre una unidad perfecta entre todos sus componentes, tampoco es una mera yuxtaposición de diversos géneros con transiciones más o menos hábilmente logradas para coser parches de distinta procedencia. Al contrario, el Protréptico se distingue entre las obras de la apologética cristiana porque transmite una sensación de notable unidad y está compuesta no para ser leída por secciones, sino del tirón, con independencia de que la sección de la refutatio (capítulos II-VII) se antoje monótona a la sensibilidad de los lectores modernos.

\footnotetext{
13 L. Emmet, «Clement of Alexandria's Protrepticus and Dio Chrysostom's Alexandrian Oration», Studia Patristica, Leuven 2001, pp. 409-414. Sobre el influjo de la diatriba filosófica, cf. Steneker, op. cit., pp. 68-70.

${ }^{14}$ Cfr. M. Rizzi, Ideologia e retorica negli «exordia» apologetici. Il problema dell' 'altro', Milano 1993, pp. 172-287. No sólo hay correspondencias anulares entre el primer capítulo y el último, sino entre los intermedios, p. ej. al ataque a los poetas griegos del cap. II corresponde la exposición de sus intuiciones de la verdad en el cap. VII.

15 G. Lazzati, L'Aristotele perduto e gli scrittori cristiani, Milano, 1937, ofrece argumentos para sostener que la obra de Aristóteles es el modelo directo de Clemente (pp. 9-34). Sin embargo, las comparaciones con el Protréptico de Jámblico y con la carta de Epicuro a Meneceo demuestran también que las características del género estaban ya extendidas entre las escuelas filosóficas, por lo que buena parte del influjo puede ser indirecto: el único pasaje del Protréptico clementino aceptado como fuente para la reconstrucción del aristotélico es Protr. 1.7.4-5 (fr. 107b, I. Düring, Aristotle's Protrepticus. An Attempt at a Reconstruction, Göteborg 1961), que coincide con la imagen de los cautivos atados a cadáveres como tortura transmitida por Cicerón y Jámblico. Cfr. U. Neymeyr, «Der Protreptikos des Clemens und des Galens», Studia Patristica 31 (2001), pp. $445-448$. Sobre el género protréptico, $c f$. S. van der Meeren, «Le Protréptique en philosophie: essaie de definition d'un genre», Rev. Ét. Gr. 115 (2002 / 2), pp. 591-621; para A. Van der Hoek, «Apologetic and Protreptic Discourse in Clement of Alexandria», L'apologétique chrétienne gréco-latine à l'époque prénicenienne, Entr. Hardt 51, 2005, Vandoeuvres-Genève, pp. 69-102, Clemente se sirve de un estilo protréptico más que de un género, lo que hace más difusa aún la posibilidad de una dependencia directa.
} 
En la búsqueda de los factores que logran esta unidad, los estudiosos han distinguido especialmente dos: el estilo y las imágenes. H. Steneker puso de manifiesto que el estilo de la obra, aunque varía en determinados pasajes para adaptarse al tema (p. ej. el desarrollo de una cita bíblica es por fuerza distinto del ataque a un mito griego) o a la necesidad retórica (el exordio y la peroratio deben ser más vibrantes que las secciones argumentativas), se mantiene en general constante a lo largo de la obra ${ }^{16}$. Por otro lado, y en consonancia con esta coherencia estilística, diversas imágenes metafóricas abundan al principio y al final de la obra, con una misma orientación: presentar el mensaje cristiano a los paganos bajo el prisma de los mitos y esquemas culturales griegos. En el capítulo I el Logos (nombre, lógicamente, mucho más adecuado a oídos griegos que Jesús o Cristo, muy escasos en comparación) se presenta como cantor a través del mito de Orfeo; en el capítulo XII utiliza a Odiseo atado al mástil para reflejar al cristiano sostenido por la cruz, y poco después se sirve de la imaginería de las Bacantes de Eurípides para presentar los misterios báquicos del Logos, «explicándolo según tu imagen»

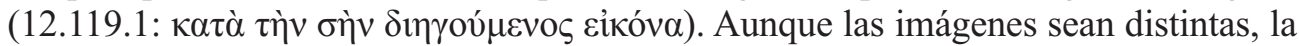
coherencia entre el principio y el cierre de la obra es total. Frente al cantor que engañaba (Orfeo), o frente a los misterios impíos (Dioniso), Clemente presenta al verdadero cantor y los verdaderos misterios. La brillantez y riqueza de éstas y otras imágenes que se repiten a lo largo de la obra las ha hecho merecedoras de múltiples estudios de detalle, por lo que no ha lugar extenderse aquí más sobre ellas ${ }^{17}$.

Sin embargo, sólo con el estilo y las imágenes la unidad del Protréptico parecería más artificial de lo que es en realidad. Más que una unidad sería una mezcla de componentes que permanecen distintos bajo una artificial apariencia de unidad. Dicho en términos informales, ambos factores son sin duda una parte importante, pero no dan con la clave de la receta del bálsamo de Clemente, que está compuesto con aglutinantes de mayor solidez que la mera continuidad estilística y las imágenes de apertura y cierre. La obra no queda retratada en una simple unidad externa que encierra contenidos dispares, sino que está vertebrada internamente por unas nociones básicas profundamente enraizadas en la mente de su autor, que orientan en un mismo sentido los diversos géneros y fuentes que recoge el Protréptico y dan idéntico fundamento a las imágenes literarias aludidas. La terminología de la semántica cognitiva habla de metáforas conceptuales para referirse a estas nociones básicas y no es cuestión de discutir aquí lo apropiado del nombre, sino de utilizar sus métodos para poner de manifiesto los elementos internos de unidad de la obra, lo cual, hasta donde alcanza mi conocimiento, no ha sido aún intentado ${ }^{18}$. Las siguientes páginas estudia-

\footnotetext{
${ }^{16}$ Steneker, op. cit., 65-140.

${ }^{17}$ Cfr. en general Steneker, op. cit., pp. 133-140; sobre los misterios, Ch. Riedweg, Mysterienterminologie bei Plato, Philo und Klemens von Alexandrien, Berlin-New York, 1987; sobre la música, E. Irwin, «The song of Orpheus and the New Song of Christ», J. Warden (ed.) Orpheus: Metamorphoses of a Myth, Toronto 1982, pp. 51-62; T. Halton «Clement's Lyre: a broken String, a New Song», Sec Cent 3 (1983), pp. 177-199; y sobre todo F. Jourdan, Orphée et les chrétiens: la reception du mythe d'Orphée dans la littérature chrétienne grecque des cinq premiers siècles: Orphée, du repoussoir au préfigurateur du Christ, vol I, Paris 2010.

${ }^{18}$ Cfr. G. Lakoff / M. Johnson, Metaphors We Live By, Chicago 1981; G. Lakoff / M. Turner, More than Cool Reason: A Guide to Poetic Metaphor, Chicago 1985.
} 
rán, pues, la presencia en el Protréptico de las metáforas conceptuales que, sin perjuicio de otros posibles elementos aún por descubrir o analizar, son las claves de unidad interna en la obra.

\section{MOVIMIENTO: LA SALVACIÓN COMO META}

El Protréptico entero es una obra de movimiento, en todos sus niveles, desde los más básicos como el título (de $\pi \rho \circ \rho \varepsilon ́ \pi \omega$ : dirigir hacia) y el estilo rápido de una prosa ágil, con citas cortas (en comparación con otros apologistas) y frecuentes transiciones, hasta los estratos más profundos del mensaje a la audiencia prevista por Clemente ${ }^{19}$. Y es que el texto se sustenta sobre una noción básica de la conversión como un recorrido que tiene como meta un punto distante al que es necesario llegar, o al menos orientarse.

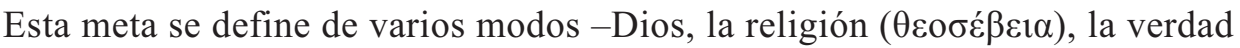

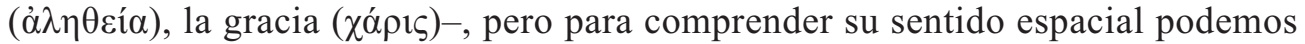
focalizarnos en el término más frecuente para señalar este objetivo, la salvación ( $\sigma \omega \tau \eta \rho i ́ \alpha)$. La palabra $\sigma \omega \tau \eta \rho i ́ \alpha$ aparece en multitud de ocasiones a lo largo de toda la obra -38 veces sin contar los adjetivos y verbos de la misma familia-. En la gran mayoría tiene un sentido explícito de objetivo al que tender: «hacia la salvación» ( describir la voluntad de Dios sobre el hombre (1.2.3, 1.8.3), acompañando a verbos que 1laman a acercarse: «llamar» $(1.7 .6,1.9 .1,10.94 .2,12.118 .5,12.123 .2$ :

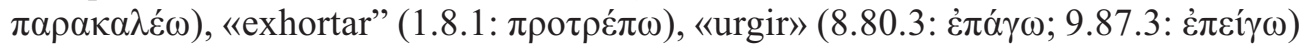
«apresurarse» (4.63.5, 9.82.3, 9.88.2: $\sigma \pi \varepsilon v ́ \delta \omega)$, «perseguir» (10.93.2: $\delta 1 \omega ́ \kappa \omega)$. Las metáforas en torno al término implican también movimiento: por ejemplo, las pro-

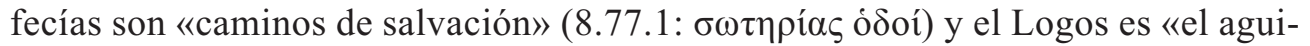

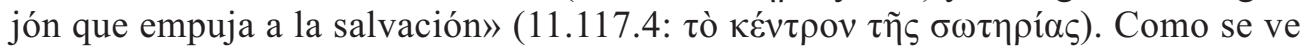
en estos ejemplos, el término aparece con especial intensidad en el primer capítulo (el exordio) y los cuatro capítulos finales, como es lógico, en que se presenta el mensaje del Logos. Sin embargo, los casos en los capítulos intermedios muestran que la refutación del paganismo tiene la misma orientación que los pasajes argumentativos: «que para la salvación te avergüencen las acusaciones contra vuestros dioses ${ }^{20}$. También en estos capítulos de ataque a la religión griega la metáfora literaria se construye sobre la misma noción básica (4.43.5): «la única vía de escape,

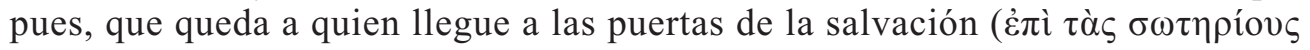

\footnotetext{
19 Sobre la audiencia del Protréptico, se trata sobre todo de cristianos convertidos pero aún no bautizados para A. von Stockhausen, «Ein “neues Lied”? Der Protreptikos des Klemens von Alexandrien», Ch. Schubert, A. von Stockhausen (eds.), Ad veram religionem reformare. Frühchristliche Apologetik zwischen Anspruch und Wirklichkeit, Erlangen 2006, pp. 75-96. A su vez, D. Dainese, «Il Protrettico ai Greci di Clemente Alessandrino: Una proposta di contestualizzazione», Adamantius 16 (2010), pp. 256-285 demuestra que la polémica antignóstica estaba también implícita en la obra.

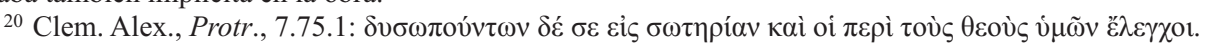




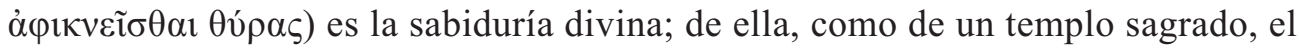

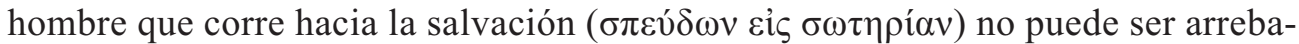
tado por ningún demonio».

El movimiento implicado en esta imagen fundamental de tender hacia una meta es la metáfora conceptual que sustenta la idea de conversión ( $\mu \varepsilon \tau \alpha ́ v o 1 \alpha)$, el verdadero núcleo del Protréptico. Este movimiento puede ser simplemente un cambio de orientación mental, basado en la imagen de un giro que permite ver lo que antes se ignoraba: «el Logos, revelando la verdad, ha mostrado la cumbre de la salvación a los

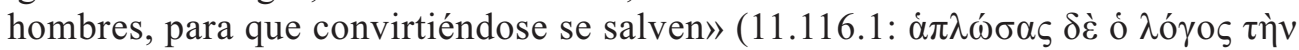

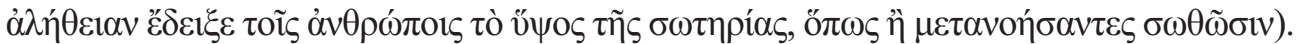
También puede presentarse como un desplazamiento, un viaje entre un punto y otro (1.8.1): «huyamos ( $\varphi v ́ \gamma \omega \mu \varepsilon v)$, pues, del príncipe de la potencia del aire... y corramos $(\pi \rho \circ \sigma \delta \rho \alpha ́ \mu \omega \mu \varepsilon v)$ hacia el Salvador, el Señor, que ahora y siempre nos llama a la salvación (cis $\sigma \omega \tau \eta \rho i ́ \alpha v) »$.

Ambos tipos de movimiento hacia la salvación, el giro y el desplazamiento, el alejamiento del paganismo para orientarse hacia la verdad cristiana, están en la base del ataque a los cultos griegos, que comienza en el libro II con un sonoro «jabandonad!» (2.11.1: $\kappa \alpha \tau \alpha \lambda \varepsilon i ́ \psi \alpha \tau \varepsilon)$. Y también son el fundamento de las continuas metáforas poéticas del exordio y la peroratio, de las que aquí basta con recordar algunas de las más célebres: «que abandonen ( $\alpha \alpha \tau \alpha \lambda \varepsilon i \pi o ́ v \tau \omega v)$ el Helicón y el Citerón, y vengan a habitar a Sión» (1.2.3); «el Espíritu (o Viento: $\pi v \varepsilon \tilde{u} \mu \alpha)$ Santo te hará llegar a los puertos celestiales» (12.118.3); «Ven, anciano, deja Tebas [...] icorre, Tiresias, cree!» (12.119.2). Lo que liga todas estas imágenes literarias entre sí no es sólo la continuidad del estilo, sino que todas ellas se sustentan sobre la misma imagen conceptual, la conversión como un movimiento hacia la salvación.

En otro lugar he analizado las consecuencias cognitivas de la metáfora espacial que subyace a la conversión, la principal de las cuales es la revalorización de lo nuevo (el punto de llegada) frente a lo viejo (el punto de partida ${ }^{21}$. Este cambio de paradigma es radical respecto a la religión griega, que veneraba la costumbre y tradición antiguas denostadas ahora por Clemente en el Protréptico ${ }^{22}$. Sin embargo, no es una innovación del alejandrino, pues es una constante de la literatura cristiana desde el Nuevo Testamento. Su mérito es amoldarlo a los cánones de un género literario griego tradicional, propio de la cultura elevada, como es el protréptico filosófico. En cualquier caso, lo que aquí nos importa es el modo en que esta imagen básica de movimiento impregna toda la obra como factor central de unidad. Sea con la imagen del desplazamiento, sea con la del giro, la delimitación de la salvación como un punto lejano al que hay que tender exige dejar claro al oyente pagano que su estado actual no está orientado a ella, sino que es un estado de engaño y condena. La salvación por defini-

\footnotetext{
${ }^{21}$ M. Herrero de Jáuregui, «La conversión como metáfora espacial: una propuesta de aproximación cognitiva al cambio cultural de la Antigüedad Tardía», Ilu 10 (2005), pp. 63-84; Dainese, op. cit. continúa profundizando en esta dirección.

${ }^{22}$ L. Lugaresi, «Fuggiamo la consuetudine: pratiche sociali cristiane, rappresentazione e spettacoli in Clemente Alessandrino», Adamantius 9 (2003), pp. 10-28.
} 
ción lo es de algún peligro concreto, y sin una percepción clara de éste la claridad de la meta se difumina, igual que la persuasión a la acción se debilita si no suscita el miedo a la inacción ${ }^{23}$. Por eso la focalización de la obra en torno al movimiento hacia la salvación exige una definición del punto de partida, que se conforma en torno a dos ejes: la polaridad y la simetría.

\section{POLARIDAD: RELIGIÓN VS. SUPERSTICIÓN}

La estructura profunda del discurso protréptico exige una oposición polar de dos opciones enfrentadas, entre las que el hombre debe elegir. No cabe una tercera opción que haría del camino propuesto una posible vía entre otras. Clemente describe el proceso de conversión no sólo como un movimiento hacia la meta, sino como el desplazamiento entre dos principios radicalmente contrarios:

Convirtámonos y pasemos de la ignorancia al conocimiento, de la insensatez a la sensatez, de la incontinencia a la continencia, de la injusticia a la justicia, del ateísmo a Dios. Es un bello riesgo cambiar de bando hacia Dios ${ }^{24}$.

La alusión al bello riesgo del Fedón platónico (114d) se adapta al tránsito entre contrarios que se definen mutuamente. Tanto peso retórico tiene el punto de partida como el de llegada. Por ello la extensa refutatio del paganismo, que ocupa la mitad de la obra, no debe verse como una concesión a la tradición apologética, que arruina la unidad y belleza de la obra, sino como el contrapeso necesario para calibrar bien la novedad y necesidad de dar el paso hacia la conversión. La metáfora judicial que impregna toda la acusación a la religión griega $(2.12 .1,14.1,15.3,16.3,22.7,23.2,27.5,32.1,39.1$, 4.62.4, 9.84.1) no es sólo una imitación retórica de los discursos deliberativos ante un jurado real, sino que conviene a la estructura polar de la obra: la audiencia debe decidir, a modo de jueces y a la vez partícipes en el juicio, entre dos causas opuestas, la gracia para uno supone la condena del otro. La última frase de la obra deja clara la opción radical e inexcusable (12.123.2): «a vosotros os queda elegir vuestro destino, la gracia o el juicio: a mí no me cabe duda de cuál es mejor de ambas: no es posible considerar igual la vida y la muerte».

Como ocurría con el movimiento, esta oposición entre contrarios se basa también en metáforas conceptuales y literarias. Las descripciones de rituales y mitos, y las alusiones despectivas a filósofos y poetas, se encuadran dentro de una serie de imágenes que construyen la oposición básica entre deisidaimonia (superstición) y theosebeia (religión). La primera supone esclavitud y engaño, la segunda libertad y ver-

\footnotetext{
23 Arist. Rhet. 1382a-1383a.

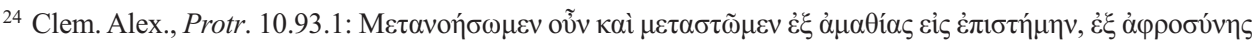

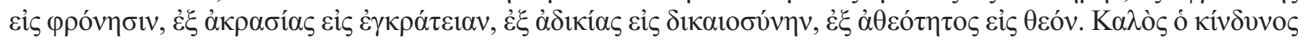

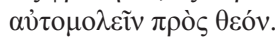


$\mathrm{dad}^{25}$. Los pares de contrarios, como sensatez frente a embriaguez, se acumulan con énfasis retórico según hemos visto. Pero de modo especial predominan dos oposiciones básicas que se fundamentan en esquemas universales: lo de arriba (lo celeste, lo divino) frente a lo de abajo (lo terrestre y humano), y la luz frente a la oscuridad ${ }^{26}$. Ambas están en consonancia con la noción de movimiento, concebido como desplazamiento espacial o como giro o cambio de orientación. La contraposición es tan evidente que basta una serie de pasajes escogidos para mostrar la ubicuidad de ambas oposiciones en toda la obra.

La oposición entre lo celeste y lo terrestre se explicita desde el principio: el Logos viene a «llamar a los cielos a los que han caído en tierra» ${ }^{27}$. En efecto, el cielo se presenta como la meta física final a la que Dios llama al hombre (10.99-100) y la tierra el lugar de la caída original del hombre arrastrado a la esclavitud del placer carnal y la corrupción material (10.101). El vínculo de Dios con lo celeste y lo pagano con lo terrestre y material no sólo se apoya en la tradición platónica, ya ampliamente compartida, sino en la tradición bíblica que contrapone la materialidad de los ídolos al Dios creador del cielo: el Salmo 95.5 se cita en Protr. 4.62 .4 como introducción a una larga sección sobre Dios, creador de los astros - cuya obra material los griegos han divinizado sin reconocer a su creador.

La oposición entre luz y oscuridad toma particular resonancia en las evocaciones literarias de la peroratio final al ritual nocturno de los misterios eleusinos, en que las antorchas iluminan el camino, que se asimila a la liturgia cristiana ${ }^{28}$. Sin embargo, es claro que la metáfora literaria se basa en una contraposición básica que liga la luz a la verdad y la oscuridad a la ignorancia, fundamento de la noción griega del conocimiento como visión. Así la oscuridad se liga al paganismo en pasajes del exordio (1.2.3:

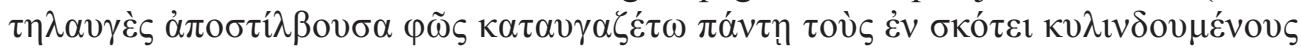

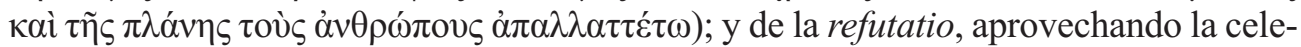
bración nocturna o subterránea de muchos cultos griegos de origen ctónico $(2.11,2.22$, 2.25). Y así de modo natural, la crítica de Heráclito a estos rituales nocturnos

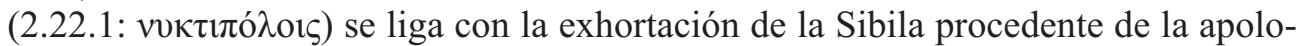
gética judía: «dejad la sombra de la noche y tomad la luz» ${ }^{29}$. Además, no es necesario abundar en que otras imágenes comunes, como la oposición entre despertar y dormir, se sustentan en esta misma oposición de fondo (p. e. 10.101.2 con la cita de Jn.3.19).

${ }^{25}$ La imagen del cambio de patrón (Protr. 10.91.2) para expresar la conversión es coherente con la noción del giro o viaje hacia la salvación: cf. Z. A. Cook, Reconceptualizing Conversion: Patronage, Loyalty and Conversion in the Religions of the Ancient Mediterranean, Berlin-New York, 2004.

${ }^{26}$ La universalidad de las imágenes orientacionales está ya expresada en [Aristot.] Cael. 285a. Ilustraciones de la oposición luz / oscuridad en la antigua Grecia, en M. Christopoulos, E. D. Karakantza, O. Levaniouk (eds.), Light and Darkness in Ancient Greek Myth and Religion, Lanham, 2010.

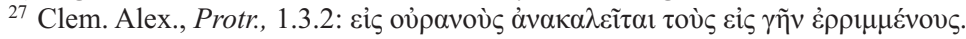

${ }^{28}$ Cfr. Ch. Riedweg, «Die Mysterien von Eleusis in rhetorisch geprägten Texten des 2/3. Jahrhunderts nach Christius», Ill. Class. Stud. 13.1 (1988), pp. 127-133; los ecos de la liturgia cristiana en F. Dölger,

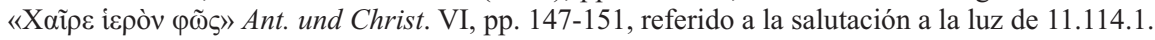

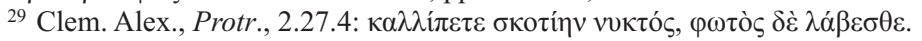




\section{SIMETRÍA: LO LEGÍTIMO Y LO BASTARDO}

Ahora bien, en todas las metáforas mencionadas, puede observarse no sólo una relación de oposición, sino de simetría. Este rasgo no es necesariamente consustancial al anterior. Deisidaimonia y theosebeia, salvación y condenación, aunque son contrarios, en principio no tendrían por qué ser el reflejo simétrico de su opuesto. De hecho, la realidad del «paganismo» era muy diferente al cristianismo, y una parte importante del estudio moderno de la religión griega sigue dedicándose a evitar la proyección de categorías cristianas que imponen su modelo a fenómenos heterogéneos.

Sin embargo, la retórica del texto clementino, como de muchos otros apologistas, es constante en su presentación simétrica de los dos campos opuestos. La fuerza de las mencionadas metáforas de movimiento entre un punto y otro, y de juicio sumarísimo entre una opción y su contraria, imponen esta simetría. Ésta se manifiesta constantemente como un factor unificador del Protréptico, en todos los niveles. Desde las igualaciones más superficiales, como la de los filósofos (cap. VI) y poetas (cap. VII) griegos como equivalente pagano de los profetas bíblicos (cap. VIII) ${ }^{30}$, a la expresión frecuente de paridad que acompaña la descripción de lo cristiano como el verdadero (őv $\tau \omega \varsigma, \dot{\alpha} \lambda \eta \theta \tilde{\omega} \varsigma$ ) equivalente de un elemento griego: los cristianos son «los misterios verdaderamente santos» (12.120.1), como el Dios cristiano es el verdadero frente a los dioses griegos $(2.23 .1)^{31}$.

A este respecto, la metáfora conceptual más poderosa y frecuente es la genealógica, que utiliza la imagen de la filiación como modo de distinguir opuestos con neta simetría. La argumentatio formula la idea explícitamente en los capítulos IX y X. En la primera parte del capítulo IX (9.82.1-6) se hilan una serie de citas homéricas y bíblicas como introducción a la idea de que los cristianos se reconocen como los hijos legítimos del verdadero padre, Dios: «hijo mío, no rehúyas la educación del Señor, y no desobedezcas al ser reprendido por Él» $(H e b .12 .5=$ Prov. 3.11), pues Él corrige a sus hijos «como un padre benévolo» (Il. 24.770) ${ }^{32}$ :

Nosotros somos hijos primogénitos, criados por Dios, amigos legítimos del Primogénito, los primeros de todos los hombres que hemos conocido a Dios, los primeros en apartarnos de nuestros pecados, los primeros en alejarnos del Diablo. Y cuanto más benévolo es Dios, más impíos son los hombres, pues Él nos quiere hacer hijos de esclavos, y ellos rehúsan ser hijos.

Frente a esta filiación divina, las lealtades de la filiación humana que llevan a respetar las costumbres de la tradición religiosa representan una paternidad falsa que no

\footnotetext{
${ }^{30}$ Quizá como respuesta a Celso, que compara a los poetas y teólogos griegos con los profetas bíblicos, respondido a su vez por Orígenes en $C C$ 1.16-18.

${ }^{31}$ Paralelos célebres en Tertuliano, Marc. 1.1.4 (Cristo como verus Prometheus); y Justino, Dial. 135.3 (los

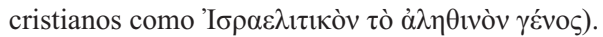

${ }^{32}$ La frase homérica era paradigmática para expresar virtud paterna (Ps. Plut. Vit. Hom. 182; Stob. 4.7.8). Cf. Zeegers, op. cit. 266. Otras citas bíblicas encadenadas en torno al tema de la filiación divina: Mt. 18.3, Jn. 3.5, $\mathrm{Hb} .18 .22-23$
} 
debe prevalecer, como dice al empezar el capítulo X (10.89.1-2): «Pero decís, hemos recibido las tradiciones de nuestros padres [...] pero aunque los padres se sientan ofendidos abandonemos la costumbre $\rangle^{33}$. Y ambas secciones están unidas con la repetición insistente de la frase clave: Dios es «el padre que verdaderamente es» $(9.82 .4=$

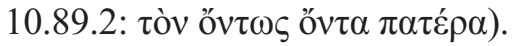

Esta contraposición entre paternidad divina y humana no se limita a estos dos capítulos, sino que impregna toda la obra: los fundadores de los cultos griegos, como Dárdano, Eetión, Midas, Cíniras, Melampo, son «padres de la superstición maldita, que sembraron en la vida los misterios, simiente del mal y de la corrupción» ${ }^{34}$; Aristóteles es «padre de la secta (de los peripatéticos) que no conoció al padre de todas las cosas $»^{35}$. También los dioses griegos se contraponen a la paternidad divina, pues su falta de ejemplaridad les impide corregir como padres (2.41.2: «el padre educa al hijo del maleducado» $)^{36}$. La crítica a las teogonías griegas incluye, como es tradicional, la burla a que los dioses se engendren unos a otros por incontinencia sexual. ${ }^{37}$ Así a la filiación de los hombres como hijos de Dios por el espíritu, cuyo descubrimiento fundamenta la theosebeia, corresponde la paternidad humana, inspirada por los demonios, de la superstición que se transmite por vía genética y carnal. De este modo, el origen del mal es excluido de la conexión genealógica con lo divino. Es una noción básica que a lo largo de toda la obra vertebra la oposición de lo cristiano y lo griego.

Pero a su vez, la simetría que ofrece la metáfora genealógica proporciona más posibilidades, pues permite explicar los paralelos del cristianismo con los cultos griegos sin embarazo alguno. Ésta era una cuestión tradicional de la polémica religiosa antigua (y moderna) cuya variedad de respuestas entre los apologistas muestra a las claras la dificultad que entrañaba ${ }^{38}$. La oposición entre descendencia legítima e ilegítima permite emparentar a lo griego como reflejo bastardo de lo cristiano y de este modo dar una explicación de la similitud que no ponga en discusión la distinción fundamental entre lo verdadero y lo falso. De este modo paradigmático, Clemente sigue en 2.25.1 a Filón (Mig. 68) en la alegoría del pasaje bíblico (Dt. 23.1) en que Moisés prohíbe la entrada en la asamblea del castrado y del hijo de la prostituta, identificando al primero con el ateo y al segundo con el supersticioso devoto de los dioses griegos. Es claro que no es una mera trasposición de un pasaje de su predecesor judío, que introduce una imagen desconectada, sino que lo hace en plena consonancia con otros pasa-

${ }^{33}$ La querencia de Clemente por las imágenes de generación sigue patente en el Pedagogo y los Stromata: cf. D. K. Buell, Making Christians: Clement of Alexandria and the Rhetoric of Legitimacy, Princeton, 1999; Why This New Race? Ethnic Reasoning in Early Christianity, New York, 2005.

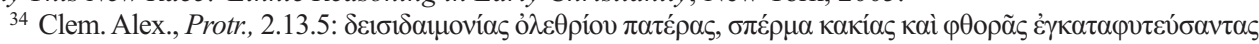

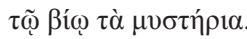

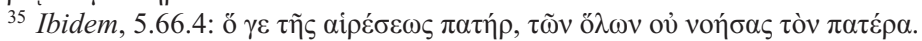

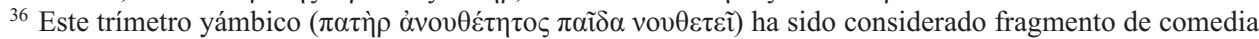
(fr. adesp. 1257 T. Kock, Comicorum Atticorum Fragmenta, Leipzig 1880-1888; no por los últimos editores, R. Kassel / C. Austin, Poetae Comici Graeci, Berlin 1983-2001), aunque quizá es una expresión proverbial.

${ }^{37}$ Clem. Alex., Protr. 2.12-22; cfr. Orig. CC 1.24-25, 4.36, 4.48; Greg. Naz. Or. 4.115, Or. 31.36.

${ }^{38}$ Cf. M. Herrero de Jáuregui, Tradición órfica y cristianismo antiguo, Madrid 2007, cap. V para la cuestión entre los apologistas y cap. I para el debate moderno. 
jes del Protréptico que tienen el mismo sentido basado en la oposición legítimo / bastardo como base conceptual de la distinción verdadero / falso, pero a su vez prevén la similitud aparente entre religión y superstición. Así cuando dice «los misterios realmente profanos y las iniciaciones carentes de rito llaman a una piedad bastarda» ${ }^{39}$ asemeja las llamadas a participar en los misterios a una copia ilegítima de su propio protréptico. Del mismo modo, esta imagen básica se combina con las de la luz vs. oscuridad y la del juicio en torno al motivo de que el águila reconoce la legitimidad de sus hijos cuando miran al sol (10.92.5): «como los hijos de la luz legítimos ( $\tau \dot{\varepsilon} \kappa v \alpha$ $\varphi \tau$ tò $\gamma v \eta ́ \sigma \iota \alpha)$ sostenemos la mirada y la dirigimos a la luz, sin que el Señor nos acuse como bastardos (vó $\theta$ ovৎ) como el sol a las águilas ${ }^{40}$. Idéntica es la noción que subyace a esta concatenación de citas bíblicas diversas bajo este hilo conductor (10.94.3):

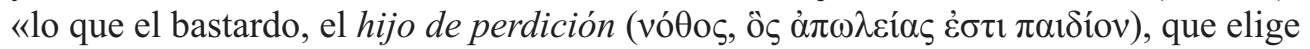
ser servidor de Mamón, lo compra con dinero, Dios te da a ti lo tuyo, al legítimo, es

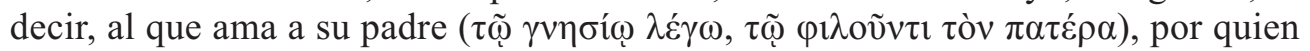
«todavía trabaja»y el único a quien promete que «la tierra no se venderá» ${ }^{41}$. El adjetivo gnesios se repite con frecuencia en toda la obra, y estas contraposiciones explícitas revelan que no es un epíteto banal incluso cuando no aparece explícitamente contrapuesto a nothos. ${ }^{42}$

De este modo, las oposiciones que distinguen los dos campos en liza, especialmente a través de la metáfora genealógica, los construyen de modo simétrico, como reflejo el uno del otro. A la vez que esta oposición simétrica legitima el ataque al paganismo como caricatura o inversión de la verdad, permite también construir puentes conceptuales que presenten al cristianismo bajo los ropajes paganos, p. ej. con las imágenes del canto y los misterios, sin contradicción con la condena a los mitos, poetas y cultos griegos. Porque, aunque los contenidos sean radicalmente opuestos, el Protréptico los categoriza en los mismos esquemas formales.

\section{CONCLUSIÓN: BASES, CUERPO Y ADITIVOS}

Es obvio que estas distinciones y categorías no son válidas exclusivamente para el Protréptico y, con variaciones, se pueden aplicar a muchas otras obras de la literatura apologética. Sin embargo, ésta logra con especial éxito la conjunción de géneros, temas, fuentes y estilos muy diferentes, que se trenzan en un discurso unitario en torno a estos engranajes de movimiento, polaridad y simetría. Las imágenes y nociones bási-

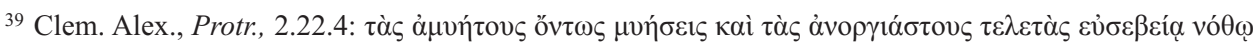

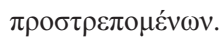

${ }^{40}$ El adjetivo $\gamma v \eta ́ \sigma ı \alpha$ es añadido por Clemente a la cita de Ef. 5.8 ( $\left.\tau \varepsilon ́ \kappa v \alpha \varphi \omega \tau o ̀ \varsigma\right)$ para integrar la cita en su esquema. La creencia popular de esta costumbre del águila en Ael. N. A. 2.26, 9.3.

${ }^{41}$ Las referencias bíblicas entrecomilladas en este párrafo son de Gn. 1.28, Jn. 17.12, Mt. 6.24, Jn.5.17, Lv. 25.23.

${ }^{42}$ Aparte de los pasajes citados, gnesios o su derivado adverbial aparece en $1.2 .3 ; 9.82 .6 ; 10.96 .3$; 10.98.4; 10.99.4 (cf. 9.90.3); 10.109.3; 10.110.3; 11.117.2.
} 
cas aquí analizadas no son probablemente las únicas que se puedan encontrar, pero sí son los más destacados y aparentes elementos de unidad conceptual, que permite ligar internamente la tradición griega y la bíblica, la retórica imperial y los tópicos de la apologética, la argumentación filosófica y la exaltación hímnica.

Podemos volver para concluir a la imagen inicial con que Clemente definía su obra, un bálsamo verdadero, dulce y persuasivo como el vino. Si nos permitimos en esta última nota, conjurado a estas alturas el riesgo de frivolidad, una analogía con la coctelería moderna, cabe recordar que los tratadistas distinguen en todo combinado tres elementos: base, cuerpo y aditivos. ${ }^{43} \mathrm{La}$ base es el elemento alcohólico fundamental, el cuerpo el ingrediente que le da el carácter propio que define al cóctel, y los aditivos aquellos que tienen una función accidental. Trasladándonos de nuevo al bálsamo del Protréptico, las bases son las fuentes y modelos analizados en la primera sección, y los aditivos serían los elementos estilísticos y formales que le dan unidad externa a la obra. Pero el cuerpo, los verdaderos factores de la unidad interna, son las metáforas básicas y esquemas conceptuales de movimiento, oposición y simetría cuya omnipresencia en la obra le da un sabor único que aún hoy llega al paladar de su lector.

\footnotetext{
${ }^{43}$ Cfr. C. Delgado, $365+1$ cócteles, Madrid 1985, que traduce la clásica distinción tripartita de D. A. Embury, The Fine Art of Mixing Drinks, 1948.
} 